See discussions, stats, and author profiles for this publication at: https://www.researchgate.net/publication/335769131

\title{
Next Generation Government - Hyperconnected, Smart and Augmented
}

Chapter · August 2019

DOI: 10.1007/978-3-030-28464-0_25

\section{CITATION}

1

1 author:

Adegboyega Ojo

National University of Ireland, Galway

172 PUBLICATIONS 1,643 CITATIONS

SEE PROFILE

Some of the authors of this publication are also working on these related projects:

Project Your Data Stories View project

Electronic Voting View project 
Cite this paper as:

Ojo A. (2019) Next Generation Government - Hyperconnected, Smart and Augmented. In:

Camarinha-Matos L., Afsarmanesh H., Antonelli D. (eds) Collaborative Networks and Digital Transformation. PRO-VE 2019. IFIP Advances in Information and Communication Technology, vol 568. Springer, Cham. https://doi.org/10.1007/978-3-030-28464-0_25

\title{
Next Generation Government - Hyperconnected, Smart and Augmented
}

\author{
Adegboyega Ojo \\ Insight Centre for Data Analytics, Data Science Institute, \\ NUI Galway, Galway, Republic of Ireland \\ adegboyega.Ojo@nuigalway.ie
}

\begin{abstract}
Achieving the Sustainable Development Goals (SDG2030) requires governments and their various institutions to be more agile, collaborate across agency boundaries and national borders, and also develop specific capabilities. Some of the required capabilities are related to developing and sustaining governance networks, digitally transforming public service delivery, building resilience structures within government for crisis and disasters, and harnessing disruptive technologies for new solutions to hitherto unsolved problems. This paper highlights how the integration of hyper-connectivity, "smartness" and Artificial Intelligence adoption within the context of the recent Post-New Public Management (NPM) paradigms can generate new capabilities to strengthen government institutions towards achieving their relevant SDG goals.
\end{abstract}

Keywords: Hyperconnectivity, Smart Government, Augmented Government, Collaborative Networks, Post-New Public Management, Artificial Intelligence

\section{Introduction}

Governments are constantly driven to meet citizen demands, operate more efficiently, tackle wicked societal challenges and meet international development and governance commitments such as those related to the Sustainable Development Goals (SDG2030) and the Open Government Partnership (OGP). Through harnessing technological innovations and adopting new public management paradigms, governments are transforming themselves to more effectively achieve their goals [I]. In particular, governments are increasingly collaborating across governance jurisdictions, national and regional borders, and are also developing new partnerships to jointly address common problems.

In the area of technological innovation, government organisations are adopting disruptive technologies such big data and loT, artificial intelligence, robotics, drones, virtual and augmented reality, and digital fabrications [2] to create new services and develop significantly more effective policies. Furthermore, they are also creating resilient data and information infrastructure through the use of blockchains (or distributed ledger) technologies [3]. 
However, this new wave of disruptive technology adoption in government is enabled by recent public management logics described as post-New Public Management Paradigms (NPM) [4]. These new public management paradigms are characterised by features such as unprecedented transparency, use of shared and integrated services/infrastructures, use of social media, reintegration of fragmented processes, performance governance, cultivation of collaborations networks, participation in public-private partnerships and engagement of citizens [4]. Summarily, these new public administration paradigms agree on the centrality of technological innovation in the improvement of service delivery and policies. These new environments also emphasize obtaining concrete benefits and producing public values from investments in disruptive technologies.

Three major paradigms that are related to recent developments in the government technology arena include Hyperconnectivity, Smartness and Al-Augmentation (the use of Al technologies to augment the capabilities of governments). While these technology paradigms individually deliver significant capabilities, their integration has the potential to radically transform governments with new robust and mutually reinforcing capabilities. This paper highlights how the integration of these three technology paradigms within the context of the post-NPMs can deliver new capabilities that could radically transform and strengthen government institutions towards greater internal efficiency, improved citizen management, more effective policies and better public services.

The objectives of the paper is threefold: I) highlight the nature of the post-NPM and the supporting government technology paradigms that characterise future government innovation environments; 2) describe some of the new government capabilities that the future government innovation environment potentially enables, and 3) highlight some of the necessary conditions for harnessing these new government capabilities.

\section{Creating the Enabling Environment}

There is a duality between public management and governance programmes and the supporting technology innovations [5]. Thus, while technological innovations are required to support the implementation of the desired reforms programmes in government environments, the effective adoption of these technologies is also contingent on the adopting environment as shown in Figure I.

Following the New Public Management (NPM) agenda which dominated governments thinking between 1985 and 2002, recent public management and governance frameworks explicitly recognise the contributions and influences of technological innovations in government change efforts [6]. Three of these recent public management and governance frameworks include Digital Era Governance (DEG), Public Value Management (PVM) and the New Public Governance (NPG). 


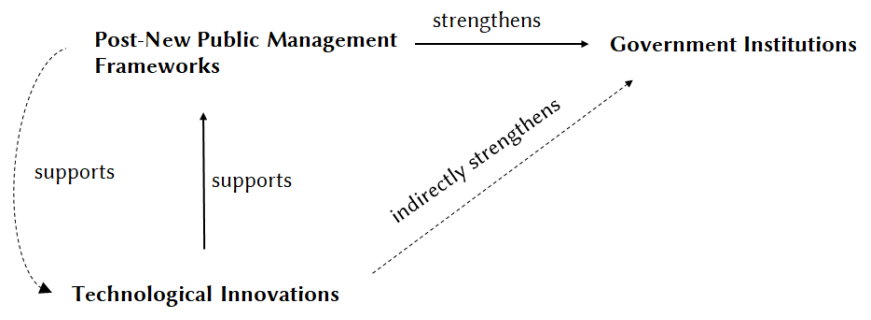

Figure I. The Duality of Post-NPM \& Technological Innovations

In the first instance, the DEG paradigm focuses on reintegrating functions in the government sphere, adopting needs-based and holistic structures in service delivery, intensifying digitalisation of administrative processes [6]. More recent models of DEG emphasise transparency, the use of social media and the establishment of shared service centres as important tenets of this paradigm [7], [8].

At the centre of the PVM paradigm is the notion of public value [9]. The concept of Public value here is more than a summation of individual preferences of citizens. The framework is characterised by: strategy-making for public value creation; performance governance and Innovation.

The NPG paradigm considers both situations where multiple interdependent actors contribute to the delivery of public services as well as the situation in which multiple processes inform policy-making systems. Core elements of the NPG paradigm include the development of networks and collaboration arrangements, forming and leveraging public-private partnerships and engagement of citizens [8]. An important assumption in this paradigm is that no single government organisation is capable of handling the type of public policy challenges facing governments today, making cooperation, collaboration, and partnering necessary [8][10].

Collectively, these paradigms employ technological innovations (or digital technologies) to drive greater openness, enable greater collaborations and new partnerships, engage citizens over new channels, track performance of governments and integrate service delivery [4]. Specific affordances of these three paradigms in contemporary public management and governance environments are given in Table $\mathrm{I}$.

Table I. Affordances of Post-NPM Paradigms

\begin{tabular}{|c|c|}
\hline PM Paradigm & What paradigm enables \\
\hline $\begin{array}{l}\text { Digital Era } \\
\text { Governance }\end{array}$ & $\begin{array}{l}\text { - } \text { Access to government information } \\
\text { - Providing information on a specific policy field of public interest } \\
\text { - Publishing open government data } \\
\text { - Getting citizens to express their opinions over social media } \\
\text { - Crowdsourcing ideas from citizens to tackle societal challenges } \\
\text { - Providing shared-service centre for delivery of integrated services }\end{array}$ \\
\hline $\begin{array}{l}\text { Public Value } \\
\text { Management }\end{array}$ & $\begin{array}{l}\text { - Public value creation } \\
\text { - Understanding public interest and delivering on them collectively } \\
\text { - Focus on long-term outcomes and not only short term results }\end{array}$ \\
\hline
\end{tabular}




\begin{tabular}{l|ll}
\hline & - Freedom for managers to be creative (out-of-the-box) and innovate \\
\hline New Public & - Development of public-partnerships to share risks and resources \\
Governance & - Joined up services and thinking across sectors \\
& - Collaboration networks of actors to tackle societal challenges \\
& - Co-production with citizens \\
& - Cialog with citizens on government performance \\
& - Creation of "publics" (different target citizen groups) \\
\hline
\end{tabular}

\section{Technological Support for Post-NPM Paradigms}

We consider three government technological (govtech) innovations that support the above post-NPM paradigms - Hyperconnected, Smart and Al-Augmented government. Collectively, these govtech paradigms provide major support for all three post-NPM paradigms. Below we describe these three govtech innovations.

\section{I Hyperconnectivity}

Hyperconnectivity is associated with a sharp increase in the interconnectedness of people, organisations and objects [ $\mathrm{II}$ ]. It is enabled by the convergence of the Internet, mobile, social media, Internet-of-things, cloud computing. The concept is also associated with the impact on personal and organisation behaviour is associated with the concept of Hyperconnectivity [12]. Hyperconnectivity focuses on collective behaviour [13] and has the following attributes [12]: perpetual connectivity; ready accessibility; information-rich; interactive; comprises varieties of connections types (machine-to-machine, people-to-machine, etc.); and virtually unlimited in storage allowing for massive data collection.

Hyperconnectivity technology such as social media offers rich information and location independent interaction endowing adopting Governments with a rich information base for policymaking. In addition, hyperconnectivity technologies such as augmented \& virtual reality could potentially allow communities to build up a shared understanding of societal and individual needs. They also support bottom-up engagement by citizens to advance their interests [14].

In addition, Hyperconnected Governments have the capability to predict individual needs for public services and the provision of personalised services based on established daily routines or patterns. Furthermore, these governments have the capability to improve communication with their constituents by sharing information more quickly and transparently. It also makes it easier for their citizens to contact them and their agents as well as access public services easily [14]. 


\subsection{Smartness}

The notion of "Smartness" in digital government literature is associated with attributes including forward-looking, innovativeness, efficiency in resource management and operations, participatory governance and citizen engagement [I5]. Smartness in the government sphere has been defined specifically to be related to creative investment in emerging technologies to achieve ability, resilient government structures and infrastructures [I][16]. According to [I], characteristics of smart government includes: inter-organisational collaboration, information sharing and integration, opening up of government and digital transformation of public services. Similarly, in [15], the notion of smart governance is associated with coordination and integration, service integration, citizen participation and co-production and design of effective regulatory policies.

Smart Governments initiatives utilize hyperconnectivity and Al technologies and a variety of technical artefacts such as interoperability frameworks and standards.

\subsection{Al-Augmentation}

Artificial Intelligence $(\mathrm{Al})$ refers to systems that exhibit intelligent behaviour by analysing their environment and taking action with some degree of autonomy to achieve specific goals [17]. Al is historically associated with computational solutions which exhibit human-like intelligent behaviour including perceiving, reasoning and acting as humans [18][19]. Five important classes of problems that could be associated with Al include: search, pattern recognition, learning, planning and induction [20].

Al technologies include [2I]: machine learning, computer vision, speech recognition, natural language processing and robotics. There are at least five emerging applications of $\mathrm{Al}$ in $\mathrm{Al}$-Augmented Governments in the context of citizen services [22]: I) answering questions; 2) filling out and searching documents, 3) routing requests, 4) translation and 5) drafting documents. In [2I], three core applications of $\mathrm{Al}$ in government include: I) robotic and cognitive automation, enabling the shifting of human labour to high-value work through technologies such as Robotic Process Automation, 2) enabling cognitive insights through better predictive capabilities; and 3) Cognitive engagement through answering citizen queries. Public sector organisations are also increasingly interested in harnessing Al capabilities and data sciences to deliver policy and generate efficiencies particularly in high uncertainty environments [23].

\subsection{Integrating Hyperconnectivity, Smartness \& Al-Augmentation}

We note here that the three Govtech paradigms described above are complementary. A closer look at these paradigms reveals that smart government paradigm is most strategic and relies on the other two paradigms for implementation. 
The hyperconnectivity generates massive data on relationships and a variety of media for citizen engagement. Al technologies are required to generate insights from hyperconnectivity data and applied to achieve smart government objectives like agility, resilience and service transformation. The interdependencies of the three govtech paradigms are depicted as a virtuous triangle in Figure 2. The capabilities enabled by three paradigms are also shown in Table 2.

These capabilities also show how the different paradigms may directly support the post-NPM paradigms described earlier in Section 2. Specifically, we observe that the Smart Government programmes are well aligned and could support DEG initiatives giving the joint focus on openness, service transformation, co-production and engagement of citizens. Smart Government programmes are also aligned with the PVM initiatives in the area of creativity. Similarly, Hyperconnected Government programmes could provide strong support for NPG initiatives by providing the capability to manage and leverage big data related to collaborations, partnerships and citizen interactions and engagement over social media. Al-Augmented programmes provide concrete services and tools to support all three post-NPM paradigms.

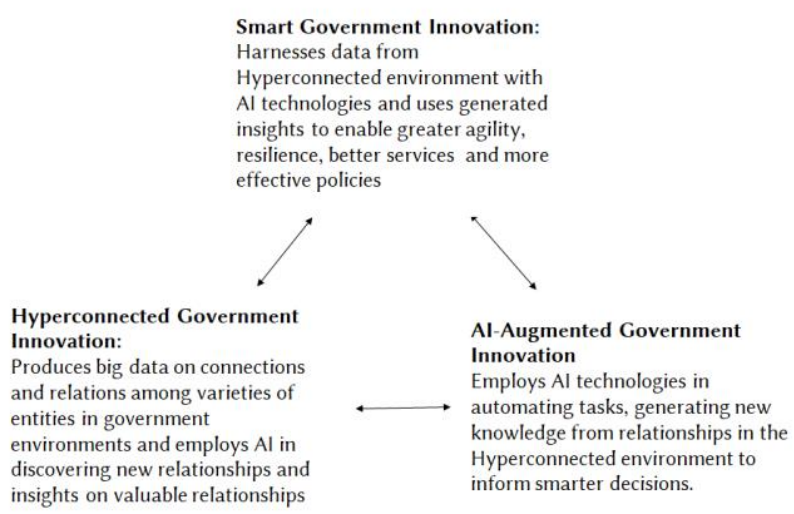

Figure 2. Integrating Govtech Paradigms

Table 2. Capabilities provided by Govtech Paradigms

\begin{tabular}{|c|c|}
\hline Govtech Paradigm & Capabilities \\
\hline Hyperconnectivity & $\begin{array}{l}\text { - Harness large amount of data and information (big data) about } \\
\text { different forms of relationships within the governance system } \\
\text { - Leverage rich information base on social media for policymaking } \\
\text { - Access to shared understanding of societal and individual needs } \\
\text { - Bottom-up engagement by citizens } \\
\text { - Predicting individual information and public service needs based } \\
\text { on interconnectivity information and delivering services over } \\
\text { preferred mobile channels }\end{array}$ \\
\hline Smartness & $\begin{array}{l}\text { - Inter-organisational collaboration and information sharing } \\
\text { - Opening up government } \\
\text { - Transformation of public services } \\
\text { - Participation, co-production } \\
\text { - Regulatory policymaking for the use of smart technologies }\end{array}$ \\
\hline
\end{tabular}




\begin{tabular}{l|ll}
\hline Al-Augmented & $\bullet$ Task automation and completion \\
& $\bullet$ Predictive \& prescriptive analytics \\
& - Cognitive engagement \& citizen question answering \\
& - Knowledge discovery and generation (through induction) \\
\hline
\end{tabular}

\section{New Capabilities enabled by Convergence}

The long-term viability of technological innovation (such as $\mathrm{Al}$ ) is contingent on effectively embedding it into the delivery of solutions for policy implementation [23]. This embedding is what we denote as convergence here. As shown in Figure 3, the technological innovation can enable new set of government capabilities when implemented in the context of the post-NPM paradigms described in Section 2. Three important capabilities that are enabled by harnessing the technological affordances (right side of Figure 2) within different post-NPM features are - hyper-openness, selfservice (DIY Government) and hyper-collaboration (see arrows).

Hyper-openness capability will allow government to deliver highly-personalised information and knowledge to citizens over old and new channels (e.g. VR) to meet their need proactively. The self-service or "Do-it-Yourself (DIY)" Government capability enables citizens and businesses to initiate the co-production of digital services they require at any time based on the tools and platforms provided by government. This capability also enables notification of citizens and businesses of services they require but unaware of.

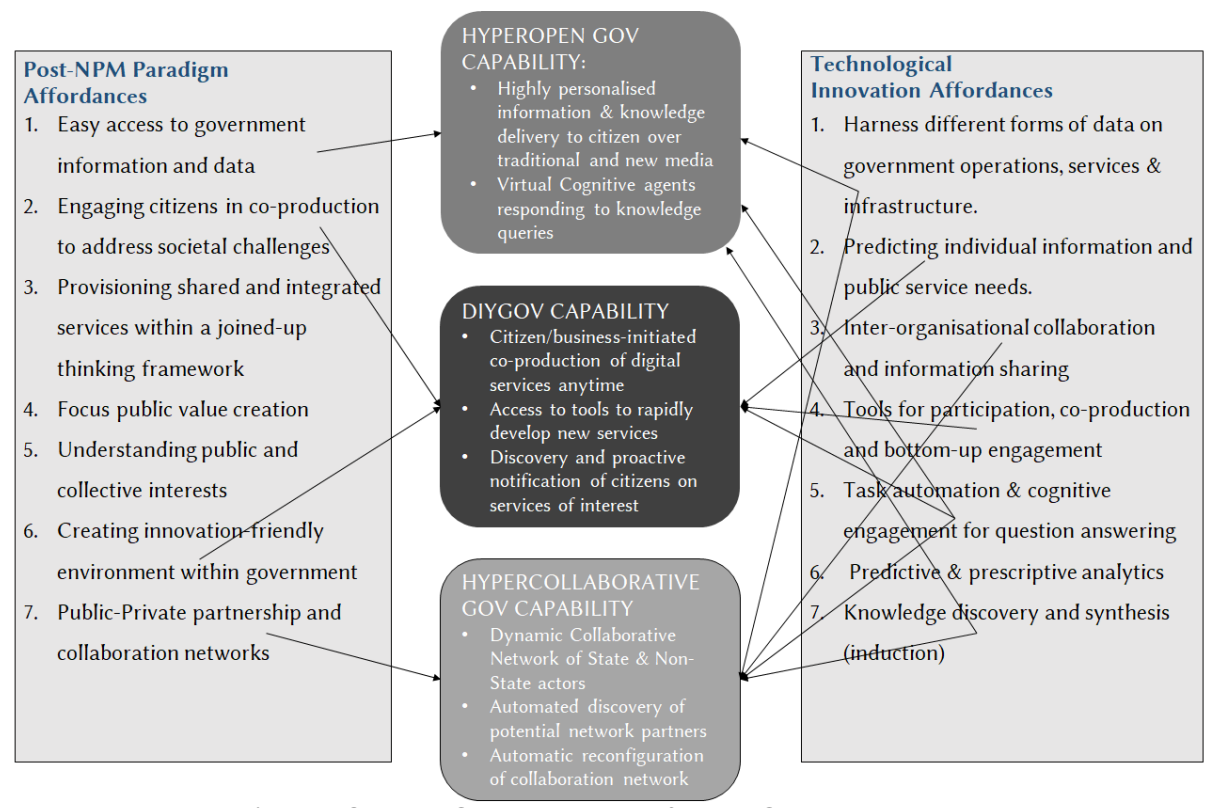

Figure 3. The Convergence of Post-Govtech Paradigms 
The hyper-collaborative Government capability enables the creation of dynamic collaboration networks [24] of state and non-state actors. This form of governance networks will be able to automatically discover and enroll partners and automatically reconfigure the network based on changing circumstances. The resulting governance networks will facilitate flexibility, speed, resource pooling and exchange as well as innovation to tackle complex societal challenges [25][26].

\section{Necessary Conditions for transitioning to Next-Gen Government}

In addition to implementing the post-NPM initiatives to create the enabling environment for implementing the above govtech innovations, there are a number of issues that must be addressed to ensure broadly: safe and ethical use of these technologies, and the availability of the requisite capacity to harness the innovations.

The first challenge is related to a large amount of data generated in hyperconnected environments. Having clear principles to resolve the ownership of individual data is very important [14], considering regulations such as the European Union's General Data Protection Regulation. Another social implication of the unprecedented transparency of public lives associated with hyperconnectivity, in particular, is the need to for stronger privacy protection in future governments [13]. The second issue is related to security. With hyperconnectivity and the use of cyberphysical systems in smart government environments, security threats are significantly amplified [13]. The third challenge is associated with the ethical use of hyperconnectivity and Al. There is ample evidence that these technologies are already being exploited for terrorist activities, including the active use social media to recruit, radicalize and plan and orchestrate violent activities. Al-powered bots are also being for disinformation purposes. Next-gen governments will have to directly address these threats which will be compounded when these innovations are integrated. Next-gen governments must address the lack of gate keepers in digital media [14] by developing the necessary regulatory framework to address disinformation and future unethical use of these innovations.

The fourth challenge is directly linked to trust issues in the next-gen Government environment enabled by highly dynamic and reconfiguration collaborative networks [24] of actors that may not have history of working together. In this kind of environments, the use of blockchains for ensuring transactions and contracts integrity will be important [2], [3].

\section{Conclusions}

By taking a convergent view on hyperconnectivity, smartness, and use of $\mathrm{Al}$ in government, this paper has outlined how new capabilities that produce stronger and 
more effective government institutions can be realised. It is however important to note that realizing these new capabilities is contingent on having the enabling public management and administration environment, such as those characterised by the postNPM initiatives. These new post-NPM environment among other things enables government institutions to harness the expertise and resources of non-state actors to directly addresses societal challenges and at the same time overcome the increasingly limited capacity of governments to effectively leverage new technological innovations like Al or hyperconnectivity [23]. More importantly, addressing the preconditions described in section 5 is a necessary first step into harnessing these new capabilities.

The new capabilities described in section 4 are related to at least two of the four scenarios of the future of government 2030+ described in [14] - DIY democracy and Super Collaborative Governments. Their "Over-Regulatocracy" scenario is related to the third challenge described in Section 5.

Our future work will elaborate on these new government capabilities to better understand possible barriers and preconditions for their development and management in future government environments.

Acknowledgments. This publication has emanated from research supported in part by a research grant from Science Foundation Ireland (SFI) under Grant Number $\mathrm{SFI} / \mathrm{I} / \mathrm{RC} / 2289$, co-funded by the European Regional Development Fund.

\section{References}

[I] J. R. Gil-Garcia, N. Helbig, and A. Ojo, "Being smart: Emerging technologies and innovation in the public sector," Gov. Inf. Q., vol. 3I, no. SI, Pp. II-I8, 2014.

[2] J. Millard, "European Strategies for e-Governance to 2020 and Beyond," in Government 3.0 - Next Generation Government Technology Infrastructure and Services: Roadmaps, Enabling Technologies \& Challenges, A. Ojo and J. Millard, Eds. Cham: Springer International Publishing, 2017, pp. I-25.

[3] A. Ojo and S. Adebayo, "Blockchain as a Next Generation Government Information Infrastructure: A Review of Initiatives in D5 Countries," in Government 3.0 - Next Generation Government Technology Infrastructure and Services: Roadmaps, Enabling Technologies \& Challenges, A. Ojo and J. Millard, Eds. Cham: Springer International Publishing, 2017, pp. 283-298.

[4] A. Ojo, F. A. Zeleti, and S. Mellouli, "A Realist Perspective on Al - era Public Management - An Analysis of Mechanisms, Outcomes and Challenges of $\mathrm{Ai}$ Solutions in the Public Sector," in In Proceedings of dg.0 2019: 20th Annual International Conference on Digital Government Research (dg.o 2019), June 18-20, 2019, 2019, pp. I-I2.

[5] W. J. Orlikowski, "The Duality of Technology: Rethinking the Concept of Technology in Organizations," Organ. Sci., vol. 3, no. 3, pp. 398-427, 1992.

[6] P. Dunleavy, H. Margetts, S. Bastow, and J. Tinkler, "New public management is dead - Long live digital-era governance," J. Public Adm. Res. Theory, vol. I6, 
no. 3, pp. 467-494, 2006.

[7] H. Margetts and P. Dunleavy, "The second wave of digital-era governance: a quasi-paradigm for government on the Web Subject Areas: Author for correspondence :," Philos. Trans. R. Soc., vol. A 37I, no. 20120382, Pp. I-17, 2013.

[8] C. Greve, "Ideas in Public Management Reform for the 2010s. Digitalization, Value Creation and Involvement," Public Organ. Rev., vol. I5, no. I, Pp. 49-65, 2015.

[9] G. Stoker, "Public Value Management: A New Narrative for Networked Governance?," Am. Rev. Public Adm. Vol., vol. 36, no. I, pp. 4I-57, 2006.

[10] S. P. Osborne, The New Public Governance - Emerging perspectives on the theory and practice of public governance. 2010.

[II] Economist, "the Hyperconnected Economy: Phase 2 Hyperconnected Organisations How Businesses Are Adapting," 2015.

[12] J. Fredette, R. Marom, K. Steinert, and L. Witters, "The Promise and Peril of Hyperconnectivity for Organizations and Societies," 2012.

[13] F. Klein, M. Bansal, and J. Wohlers, "Beyond the Noise: The Megatrends of Tomorrow's World," 2017.

[14] Joint Research Centre (JRC) of the European Commission, The Future of Government 2030+ - A Citizen Centric Perspective on New Government Models. 2019.

[15] A. Ojo, E. Curry, and T. Janowski, "Designing Next Generation Smart City Initiatives -Harnessing Findings and Lessons from a Study of Ten Smart City Programs," in Proceedings of the European Conference on Information Systems (ECIS) 2014, Tel Aviv, Israel, June 9-I I, 20I4, 20I4, pp. 0-14.

[16] S. Mellouli, L. F. Luna-Reyes, and J. Zhang, "Smart government, citizen participation and open data," Inf. Polity, vol. 19, no. I-2, pp. I-4, 2014.

[17] Europeam Commission, "Communication from the Commission to the European Partliament, the European Council, The Council, The European Economic and Social Committee and teh Committee of the Regions Coordinated Plan on Artificial Intelligence," 2018.

[18] E. A. Feigenbaum, "Artificial Intelligence Research," IEEE Trans. Inf. Theory, no. October, pp. 248-253, 1962.

[19] H. A. Simon, "Artificial intelligence: an empirical science," Artif. Intell., vol. 77, no. I, pp. 95-127, 1995.

[20] M. L. Minsky, "Steps toward Artificial Intelligence," in Proceedings of the IRE, I96I, vol. 49, no. I, pp. 8-30.

[2I] P. Eggers, William D.; Schatsky, David; Viechnicki, "Al-Augmented government," p. 28, 2017.

[22] H. Mehr, "Artificial Intelligence for Citizen Services and Government," 2017.

[23] S. J. Mikhaylov, S. J. Esteve, and S. J. Campion, "Al for the Public Sector: Opportunities and challenges of cross-sector collaboration," Philos. Trans. $R$. Soc. A, vol. 376, no. 2128, pp. I-26, 2018.

[24] L. M. Camarinha-matos and H. Afsarmanesh, "Value creation in a knowledge society," in International Federation for Information Processing (IFIP), Volume 207, Knowledge Enterprise: Intelligent Strategies In Product Design, Manufacturing, and 
Management, 2006, vol. 207, pp. 26-40.

[25] E. Estevez, A. Ojo, and T. Janowski, "Idioms for Collaborative Government Networks - Conceptualization and Applications to Seamless Services," Networks, pp. I-8.

[26] A. Ojo and S. Mellouli, "Deploying governance networks for societal challenges," Gov. Inf. Q., vol. 35, no. 4, pp. SI06-SII2, 2018. 